\title{
Oral hygiene practice among the primary school children in selected rural areas of Bangladesh
}

Sarwar AFM ${ }^{a}$, Kabir MH ${ }^{b}$, Rahman AFMM ${ }^{e}$,Haque $A^{a}$ Kasem MA ${ }^{a}$, Ahmad SA ${ }^{c}$, Debnath $P K^{a}$, Mallick PC ${ }^{a}$, , Haque $M^{a}$, Hossain $K A^{a}$, Khan $S I^{a}$, Ahmed $A H H U^{d} \&$ Parveen $S^{a}$.

\section{a. Dhaka Dental College}

1 AFM Sarwar BDS, MPH(OEH), M. Phil (PSM),Lecturer, Children, Preventive and Community Dentistry

2 Anwara Haque BDS, MPH(HM),Assistant Professor \& Head, Department of Dental Public Health

3 Prof. Dr Md. Abul Kasem BDS, DDS,Principal \& Head, Children, Preventive and Community Dentistry

4 Pradip Kumar Debnath BDS, MPH,Lecturer, Children, Preventive and Community Dentistry

5 Parimal Chandra Mallick BDS, PhD(Japan),Assistant professor \& Head Department of Dental Radiology

6 Md. Manjurul Hoque BDS, MPH, Lecturer, Children, Preventive and Community Dentistry

7 Kh. Altaf Hossain B.Sc, BDS, DOS, MCPS, Assistant Professor \& Head, Department of Dental Pharmacology

8 Sirajul Islam Khan BDS, Lecturer, Oral Aanatomy and Hhistology

9 Saleha Parveen BDS, DDS, Assistant Professor, Department of Chemistry of Dental Science

b. Shaheed Suhrawardy Medical College: Md. Humayun kabir BDS, DDS, Assistant Professor of Dentistry

c. NIPSOM: Prof.(Dr.) SK Akhtar Ahmad MBBS, MPH, Professor \& Head, DOEH, NIPSOM

d. BSMMU: Abu Hena Helal Uddin Ahmed, BDS, MS(Prosthodontics), Medical Officer, Department of Prosthodontics.

e. HFRCMC: Prof. (C.C) A.F.M. Mohibur Rahman, Head of the department of Pharmacology, Holy Family Red Crescent Medical College

\begin{abstract}
:
Objectives: To determine the oral hygiene practices, periodontal status and bad mouth breath (BMB) among the children age between 5 to 15 years. Study participants and methods: This was a cross sectional descriptive study conducted at at four-selected primary school at Fultola and Juri Upazilla of Moulovi Bazar District. Total 250 children aged 5-15 years, were interviewed on oral hygiene practices and BMB using structured questionnaire and a checklist. Oral hygiene and periodontal status were assessed by using disposable dental explorer and a dental mirror. Results: Oral hygiene practice were ; where $(66.8 \%)$ non tooth brush and tooth brush users were $(33.2 \%)$. The prevalence of dental caries plaque, gingival bleeding and BMB on probing was $(69.6 \%),(91.6 \%),(66.8 \%)$ and $(64 \%)$ respectively. Conclusion: Bad mouth breath is a cause of concern among children associated significant factors were gum bleeding. Research involving clinical diagnosis of bad mouth breath and intervention through oral health promotion and periodontal therapy are recommended. Clinical relevance: This study provides baseline information on oral health status and bad mouth breath which necessitates in the future need for objective assessment, diagnosis and management of bad mouth breath for enhanced social and professional interaction without embarrassments.
\end{abstract}

Key words: bad mouth breath; bleeding gum; calculus, oral hygiene;

\section{Introduction:}

Oral health is integral to general health ${ }^{1}$; nobody cannot be healthy without oral health. Many general diseases manifest in the mouth, and oral disease may be the first indication of other life-threatening disease. Emerging evidence has shown a strong link between the effects of chronic oral inflammation and general health. The mouth is the visible gateway to the rest of the body and reflects what is happening deep inside. Periodontal disease has been linked to systemic disease; likewise, systemic disease can have an impact on oral health. In fact, there are over 100 systemic diseases that have oral manifestations, such as cardiovascular disease, stroke, respiratory infections, pancreatic cancer, diabetes, and nutritional problems. Good dental hygiene can dramatically affect the quality of a person's life, affecting such things as chewing, eating, swallowing, speaking, facial aesthetics, and social interaction. ${ }^{2}$ Dental public health represents a new non-clinical specialty, which refers to dental health care evaluation and dental health promotion in order to meet the population needs ${ }^{3-4}$. The oral cavity is known to be a reservoir for pathogens to grow and thrive. Poor oral hygiene can lead to complications such as gingivitis, halitosis, xerostomia and plaque formation Determinants of the diseases have as the complex chain of environmental and behavioral events ${ }^{3}$ such as mother's education, parental smoking practices, oral health behavior, oral hygiene level, dietary habits ${ }^{5}$, and are shaped by broader socioeconomic and socio-demographic condition. $^{3}$ The most of the common dental disease can be controlled only if the individual patient exercises a considerable measure of initiative and responsibility. Therefore, individual motivation toward better oral hygiene and regular professional care is a major key to dental health ${ }^{6}$ dental caries and periodontal diseases 
are the common oral diseases showing striking geographic variations, socio-economic patterns and severity of distribution all over the world. ${ }^{7}$ It is known that oral hygiene (Greek hygienos) is the condition or practice of maintaining the tissues and structures of the mouth in healthy state ${ }^{8-9}$. Good oral hygiene has always been the milestone of public and private dental health promotion. The single most continuous theme of preventive and public health dentistry has been and remains the cleaning of teeth ${ }^{10}$ so bad oral hygiene depends on outcome dimensions comprise oral health status, impairment of function and reduced quality of life, and the negative impact of poor oral health on general healt. ${ }^{1}$ The term halitosis to describe as oral mal-odor or bad breath ${ }^{\mathbf{1 1}}$ or foetor ex ore ${ }^{\mathbf{1 2}}$ is influenced by a combination of several factors. There are also numerous non-oral sites and systemic causes have been suggested (nasal inflammation, chronic sinusitis, diabetes mellitus uremia etc.) an estimated $80-90 \%$ of all bad breath originate in the mouth itself ${ }^{11}$ generally associated with poor oral hygiene, dental plaque, dental caries, gingivitis, stomatitis, periodontitis, tongue coating, and oral carcinoma xerostomia or dry mouth. ${ }^{5,13}$ It is well accepted that the pathogenesis of oral mal odor is associated with the bacterial degradation of sulpher containing amino acids into volatile sulpher compounds of which hydrogen sulphide methyl marcaptan and to a lesser extent dimethyl sulphide are the principal components. In addition other compounds in mouth air may alsobe offensive. There are non-sulpher containing products such as volatile aromatic compounds (indole, skatole), organic acids (acetic, propionic) and amine i.e. cadaverine. Bad odor breath after awaking from night's sleep is a common condition known as morning breath, this problems tends to be in contrast to the persistent halitosis. Both of the malodor conditions appear to result in great part from the above-mentioned excessive quantities of sulpher containing gases of bacterial origin. It has been postulated that decreased salivation during sleep promotes bacteria proliferation that releases offending gases. Any oral site where microbial accumulation and putrefaction can occur is suspected to producing volatile sulpher compounds. The sites that most commonly produce intra oral bad breath are the tongue and inter dental and sub gingival areas and the tongue is considered to be largely responsible for it. More over different oral hygiene procedures for preventing oral bad breath such as tooth brushing, dental prophylaxis; flossing and tongue scraping contribute to the problem when they are inefficiently performed. Thus the aim of this study was to find out the oralmalodor ${ }^{11}$ or the bad breath originated from the oral cavity So the single most important advice in relation to good oral health is to regular visit dentist. Some good practices, may help minimize the risk of dental erosion or caries from whatever source they may arise: such as Brush teeth twice a day with a fluoride toothpaste if needed, avoid eating or drinking acidic food \& drinks just before bedtime. It is unwise to brush teeth directly after consuming an acidic food or drink, since the enamel can be temporarily weakened by being exposed to these foods. ${ }^{14}$. The oral health practice should be start at the birthday of an infant and the common problems are in his age are as oral thrush, teething blues, baby bottle caries, crying babies and diarrhea due to overlook oral hygiene of the babies. A clean damp cloth should be wrapped around the index finger to clean the gum pads, inner cheeks, lips and the tongue but nylon and pure cotton (its fibers can irritate) should not be use as because the risk of injuries on the tender lining of the oral cavity. Never allow to brush themselves as they don't have the required dexterity and use the brush as a toy, dirtying it and infecting themselves by using it again. It is one of the factor for diarrhea in some countries. Brushing of teeth of the child twice daily till he or she reaches the age of five. ${ }^{15}$

The various tools used globally are: Toothbrushes and tooth paste which can be fluoride or fluoride-free and medicated. Fluoride-free toothpastes are not advised in endemic fluoride areas. Fluoride strengthens the enamel against acidic attack but excessive fluoride mottles the teeth and causes skeletal fluorosis, Medicated pastes should be used only on prescription. Herbal chew sticks like Azadirachta Indica (Neem, Indian Lilac, Margosa Tree), Acacia arabica /Acacia nilotica (Babool, Kikar, Indian gum tree) are the preferred though many more herbal equivalent must be in use around the world and easy availability and free of cost for the poor. Dental powders are used to clean the teeth with fingers or tooth brushes. They are cheap and hence affordable.. All have their benefits and should be given the due consideration. The other tools are dental floss, tongue cleaners and mouthwashes ${ }^{16}$.

\section{Methods and Materials:}

This cross sectional study was designed to determine the oral hygiene and the oral health status among the oral hygiene practicing school children of who were reading in class I to class V. The study was carried out $25^{\text {th }}$ to $26^{\text {th }}$ October 2008 at four-selected primary school at Fultola and Juri Upazilla of Moulovi Bazar District. A total of 250 children of class I to class V from above mentioned school were included. This rural school -based cross-sectional descriptive study carried out in Bangladesh, whereby the study populations were interviewed about oral health, oral hygiene practices, gum bleeding, presence of unpleasant or bad mouth breath, number dental caries with the help of disposable dental explorer and a dental mirror with a structure questionnaire and a checklist examined oral health clinically. Oral hygiene practices included tooth brushing, frequency and specific time 
of brushing using of tooth cleaning tools like brush, finger, and tree stick For clinical examination, respondents were seated on a portable dental chair with artificial light for periodontal conditions: plaque or calculus, dental caries and gingival bleeding on gentle probing.

The data were then entered into computer and analyzed using the Statistical Package for Social Sciences (SPSS) 11.5 for Windows. Data analysis included generation of frequencies for all variables and later on data transformations were done: recode for example to generate age groups; Cross-tabulations were generated for socio-demographic information, periodontal conditions and bad mouth breath variable; whereby Pearson chisquared and Student's t-tests were applied to test the difference between groups for the categorical and continuous variables respectively. The results are presented as prevalence for categorical variables together with chi-squared test.

\section{Result:}

The study was carried out in 139 male and 111 female children among them $78 \%$ of the children were in the age group of 6-10 years and $87.2 \%$ of their parents income lies in the range of taka $5000 /=$ or below. (Table No. 01) Oral hygiene practice (Cleaning of the tooth and its associated structure in the oral cavity) was to be found $100 \%$ whereby frequency of brushing without any materials was $7.2 \%$ but used to rinse the mouth with water as the only means of keeping their oral cavity clean. Majority of the students $(40.4 \%)$ used ash and followed by tooth powder $29.2 \%$, tooth paste (12\%) and charcoal (11.2\%) In this study it was found that most of the students were habituated regarding cleaning of oral cavity in the morning $(76.8 \%)$ and twice per day (23.2\%). Majority (62.4\%) of them not use toothbrush. (Table No. 02) The occurrence of dental caries (69.6\%), plaque or calculus were found $(91.6 \%)$ gingival bleeding $(66.8 \%)$ and halitosis or BMB (64\%).(Table No. 03). The study results shows that dental caries, plaque or calculus, gingival bleeding and oral hygiene practicing methods had statistically significance differences with the halitosis or BMB. (Table No. 04, 05, 06 and 07)

Table No. 01.

Frequency distribution of the students in relation to age group, gender and monthly income of the parents

\begin{tabular}{|l|c|c|}
\hline Age in group & Frequency & Percent \\
\hline age are <=5 years & 6 & 2.4 \\
\hline $\begin{array}{l}\text { age are in between 6-10 } \\
\text { years }\end{array}$ & 195 & 78.0 \\
\hline age are >=11 years & 49 & 19.6 \\
\hline Total & 250 & 100.0 \\
\hline Gender & & \\
\hline Male & 139 & 55.6 \\
\hline Female & 111 & 44.4 \\
\hline
\end{tabular}

\begin{tabular}{|l|c|c|}
\hline Total & 250 & 100.0 \\
\hline $\begin{array}{l}\text { Monthly income of } \\
\text { parents in a group }\end{array}$ & Frequency & Percent \\
\hline Income <= 5000 & 218 & 87.2 \\
\hline Income 5500 to 10000 & 26 & 10.4 \\
\hline Income 11000 to 15000 & 2 & .8 \\
\hline Income $>15000$ & 4 & 1.6 \\
\hline Total & 250 & 100.0 \\
\hline
\end{tabular}

Table No. 01 Shows age and gender of which highest proportion $(78 \%)$ out of 250 were in the age group of 6-10 years. The table also showed that male-female ratio was 139:111, represents the monthly income of the parents also observed that $87.2 \%$ income level was <tk. 5000, $10.4 \%$ was in the income group of Tk. (5500-10000) and only $2.4 \%$ had tk. $>11000$.

Table No 02: Oral Hygiene practicing time, practice material and practice media

\begin{tabular}{|l|c|c|}
\hline $\begin{array}{l}\text { Oral hygiene practice } \\
\text { time }\end{array}$ & Frequency & Percent \\
\hline At morning & 192 & 76.8 \\
\hline Two times & 58 & 23.2 \\
\hline Total & 250 & 100.0 \\
\hline & & \\
\hline $\begin{array}{l}\text { Oral hygiene practice } \\
\text { material }\end{array}$ & 18 & 12.0 \\
\hline Without any materials & 30 & 11.2 \\
\hline Tooth paste & 28 & 29.2 \\
\hline Char coal & 73 & 40.4 \\
\hline Tooth powder & 101 & 100.0 \\
\hline Ash & 250 & 100.0 \\
\hline Total & 83 & 33.2 \\
\hline & 167 & 66.8 \\
\hline $\begin{array}{l}\text { Oral hygiene practice } \\
\text { media }\end{array}$ & 250 & \\
\hline Brush user & & \\
\hline Non user & & \\
\hline Total & & \\
\hline
\end{tabular}

Table no. 02 shows that $76.8 \%$ respondents had the experience of one time oral hygiene practice mainly at morning, $23.2 \%$ had the same at morning and night, the table also shows that $40.4 \%$ were using ash during oral hygiene practice, $29.2 \%$ were using tooth powder while $12 \%$ were using tooth paste, $11.2 \%$ were charcoal user but $7.2 \%$ were practicing oral hygiene without any materials. It is also observed that $66.8 \%$ respondents were not using tooth brush as a tooth cleaning tools but $33.2 \%$ were using tooth brush.

Table No. 03: Frequency distribution of oral and dental problems

\begin{tabular}{|l|c|c|}
\hline Dental caries & Frequency & Percent \\
\hline Yes & 174 & 69.6 \\
\hline No & 76 & 30.4 \\
\hline Total & 250 & 100.0 \\
\hline Gingival plaque or calculus & & \\
\hline Yes & 229 & 91.6 \\
\hline
\end{tabular}




\begin{tabular}{|l|c|c|}
\hline No & 21 & 8.4 \\
\hline Total & 250 & 100.0 \\
\hline Gingival bleeding & & \\
\hline Yes & 167 & 66.8 \\
\hline No & 83 & 33.2 \\
\hline Total & 250 & 100.0 \\
\hline Halitosis or BMB & & \\
\hline Yes & 160 & 64.0 \\
\hline No & 90 & 36.0 \\
\hline Total & 250 & 100.0 \\
\hline
\end{tabular}

The table No. 03 shows that $69.6 \%$ children were suffering from dental caries, $91.6 \%$ gingival plaque or calculus, $66.8 \%$ gingival bleeding and $64 \%$ halitosis or BMB

Table No. 04 Distribution of Caries with regards to Halitosis (BMB)

\begin{tabular}{|l|c|c|c|c|}
\hline Caries in tooth & \multicolumn{2}{|c|}{ Halitosis* } & \multirow{2}{*}{ Total } & $\begin{array}{c}\text { Test of } \\
\text { significance }\end{array}$ \\
\cline { 2 - 3 } & Yes & No & & \\
\hline Yes & $\begin{array}{c}122 \\
(76.3)\end{array}$ & $\begin{array}{c}52 \\
(57.8)\end{array}$ & 174 & \\
\hline No & 38 & 38 & 76 & \multirow{2}{*}{$\begin{array}{c}\chi_{(1)}^{2}=9.29 \\
\text { p }<0.05 \\
\text { Significant }\end{array}$} \\
\hline Totals & $(23.8)$ & $(42.2)$ & & \\
\hline & 160 & 90 & 250 & \\
\hline
\end{tabular}

* Percentages are shown in parentheses

$\chi_{(1)}^{2}=9.29 \mathrm{p}<0.05 \quad$ Statistically significant

The table No. 04 shows that $76.3 \%$ children had dental caries among those who were suffering from oral malodor or BMB on the other hand $64 \%$ had BMB among those who had tooth decay and was to be found statistically significant differences between Halitosis \& Dental caries $(\mathrm{p}<0.05)$

Table No. 05 Distribution of Gingival plaque with regards to Halitosis (BMB)

\begin{tabular}{|c|c|c|c|c|}
\hline \multirow{2}{*}{$\begin{array}{l}\text { Gingival } \\
\text { plaque } \\
\text { or } \\
\text { calculus }\end{array}$} & \multicolumn{2}{|c|}{ Halitosis* } & \multirow[t]{2}{*}{ Total } & \multirow{2}{*}{$\begin{array}{c}\text { Test of } \\
\text { significance }\end{array}$} \\
\hline & yes & no & & \\
\hline yes & $\begin{array}{c}152 \\
(66.4)\end{array}$ & $\begin{array}{c}77 \\
(33.6)\end{array}$ & 229 & \multirow{3}{*}{$\begin{array}{c}\chi_{(1)}^{2}=6.68 \\
p<0.05 \\
\text { Significant }\end{array}$} \\
\hline no & $\begin{array}{c}8 \\
(38.1)\end{array}$ & $\begin{array}{c}13 \\
(61.9)\end{array}$ & 21 & \\
\hline Total & $\begin{array}{l}160 \\
(64)\end{array}$ & $\begin{array}{c}90 \\
(36)\end{array}$ & 250 & \\
\hline
\end{tabular}

* Percentages are shown in parentheses

$\chi_{(1)}^{2}=6.68 \mathrm{p}<0.05 \quad$ Statistically significant

Table No. 05 shows that $66.4 \%$ children had dental plaque among those who were suffering from oral malodor or $\mathrm{BMB}$ on the other hand $64 \%$ had BMB among those who had gingival plaque and was to be found statistically significant differences between Halitosis \& gingival plaque $(\mathrm{p}<0.05)$

Table No. 06 Distribution of Gingival bleeding with regards to Halitosis (BMB)

\begin{tabular}{|l|c|c|c|c|}
\hline Gingival & \multicolumn{2}{|c|}{ Halitosis* } & Total & \multirow{2}{*}{$\begin{array}{c}\text { Test of } \\
\text { significance }\end{array}$} \\
\cline { 2 - 4 } bleeding & yes & no & & \\
\hline yes & $\begin{array}{c}115 \\
(68.9)\end{array}$ & $\begin{array}{c}52 \\
(31.1)\end{array}$ & 167 & \\
\hline Total & $\begin{array}{c}45 \\
(54.2)\end{array}$ & $\begin{array}{c}38 \\
(45.8)\end{array}$ & 83 & $\begin{array}{c}\chi_{(1)}^{2}=5.16 \\
\mathrm{p}<0.05 \\
\text { Significant }\end{array}$ \\
& $\begin{array}{c}160 \\
(64)\end{array}$ & $\begin{array}{c}90 \\
(36)\end{array}$ & 250 & \\
\hline
\end{tabular}

* Percentages are shown in parentheses

$\chi_{(1)}^{2}=5.16 \mathrm{p}<0.05 \quad$ Statistically significant

Table No. 06 shows that 160 students out of 250 had BMB among them $68.9 \%$ were suffering from gum bleeding and $64 \%$ were suffering from $\mathrm{BMB}$ or halitosis and was found statistically significant $(\mathrm{p}<0.001)$

Table No. 07 Distribution of toothbrush user with regards to Halitosis (BMB)

\begin{tabular}{|l|c|c|c|c|}
\hline \multirow{2}{*}{$\begin{array}{c}\text { Brushing } \\
\text { Technique }\end{array}$} & \multicolumn{2}{|c|}{ Halitosis* } & Total & $\begin{array}{c}\text { Test of } \\
\text { significance }\end{array}$ \\
\cline { 2 - 4 } $\begin{array}{l}\text { Brush } \\
\text { user }\end{array}$ & $\begin{array}{c}41 \\
(49.4)\end{array}$ & $\begin{array}{c}42 \\
(50.6)\end{array}$ & 83 & \\
\hline Non user & $\begin{array}{c}119 \\
(71.3)\end{array}$ & $\begin{array}{c}48 \\
(28.7)\end{array}$ & 167 & $\begin{array}{c}\chi_{(1)}^{2}=11.5 \\
\text { P<0.05 } \\
\text { Significant }\end{array}$ \\
\hline Total & $\begin{array}{c}160 \\
(64)\end{array}$ & $\begin{array}{c}90 \\
(36)\end{array}$ & 250 & \\
\hline
\end{tabular}

* Percentages are shown in parentheses

$\chi_{(1)}^{2}=11.5 p<0.05 \quad$ Statistically significant

Table No.07 shows that 160 students out of 250 had BMB among them $71.3 \%$ were non tooth brush user but those who were tooth brush user they had the same 49.5 and was to be found statistically significant $(\mathrm{p}<0.001)$

\section{Discussion}

This study was undertaken with aim to determine the oral malodor or BMB of selected primary school children in relation to oral hygiene practice in terms of timing, tools and material used as because oral health is an essential and integral component of general health throughout the life and hence affects the total well being of individuals assessment of oral health is important to decide a treatment plan for dental public health programme ${ }^{17}$. Over the last few years halitosis has been of interest both to the scientific community and to people who suffer from it. In this study $91.6 \%$ halitosis was to be found. The result indicate that lack of oral hygiene had in impact on tooth brushing ${ }^{11}$. A study from Tanzania shows the prevalence of S-BMB was $14 \%^{18}$ in a group of young mother but in this 
study it was $64 \%$ because of poor oral hygiene practice. It is known that disorders of the oral cavity cause $80 \%$ to $90 \%$ of halitosis. Anaerobic bacteria within the oral cavity are responsible for bad breath. They degrade the sulfur containing amino acids cystine, cysteine, and methionine to the foul-smelling VSCs. Halitosis of oral origin is associated with poor oral hygiene, dental plaque, dental caries, gingivitis, stomatitis, periodontitis, tongue coating, and oral carcinoma. It is believed that the bacterial mass located at the posterior dorsum of the tongue is the principal site where malodorous compounds are produced. ${ }^{19}$ Moreover there are no universally accepted standard criteria, objective or subjective that define a halitosis patient, in Japan it was measured by VSCs and found 6-23\% of halitosis. So according to above-mentioned data may reflect a major oral health concern of the public around the world. Another study on geriatric people in USA established $24 \%$ halitosis, some authors also established that $50 \%$ of the middle aged group of people had the same ${ }^{20}$ but this study was carried out only on primary school children. So lack of awareness and proper motivation on the part of the parents as well as the teachers of the schools to seek periodic preventive oral health checkups and restorative care of their children ${ }^{21 .}$ Most of the oral diseases, like most chronic pathologies in general, are directly related to lifestyle, which can be considered a public health problem due to its high prevalence and significant social impact ${ }^{104}$. The study shows that oral hygiene practices, in particular, the daily tooth cleaning without tooth brush high $(63.8 \%)$ and tooth brush user $(33.2$ $\%)$. Most of the respondents reported to be brushing on daily basis mainly at morning (76.8\%) and two times $23.2 \%$ and this may be one of the factors for high prevalence of poor oral hygiene as depicted by the presence of plaque, calculus, caries, gingival bleeding and BMB in this study population. The similar type of finding was found in a study at Tanzania within the study population, the factors significantly associated to $\mathrm{BMB}$ were gum bleeding and gingival plaque enhanced by tooth caries.

\section{Conclusion:}

In conclusion, findings from the current study are that bad mouth breath is a cause of concern among primary school children and significantly associated factors includes gum bleeding on oral hygiene practice by oral hygiene practicing materials and tooth decay.

\section{References}

1. Oral health, Over view [Online].[cited 2001 August 14]. Available from URL:http;//www.gov/healthypeople/doccu ment/HTML/volume2/21oral.htm
2. Mary SH, Ryan JH. The Importance of Oral Health in Long-Term Care. J Am Med Dir Assoc 2009;10: 667-671.

3. Manuc D, Bulgaru S, Iancu. International perspectives on correlation of CIO behavioral risk factors with dental caries journal of preventive medicine 2006;14(12):46-59.

4. Ogundele B.O, Ogunsile SE. Dental Health Knowledge, Attitude and Practice on the Occurrence of Dental Caries Among Adolescents in a Local Government Area (LGA) of Oyo State, Nigeria Asian Journal of Epidemiology. 2008;1( 2):64-71.

5. Namal N, Vehit HE, Can G. Risk factors for dental caries in Turkish preschool children. Journal of Indian Society of Pedodontics and Preventive Dentistry. 2005;23(3):115-118.

6. Rosalie H, Tash BS, Robert MO, Lois KC. Testing a preventive-symptomatic theory of dental health behavior a dental health behavior theory. A.J.P.H. March, 1969;59(3):514-521.

7. Rai B, Jain Rajnish, Duhan J, Anand SC. Relationship Between Dental Caries And Oral Hygiene Status Of 8 To 12 Year Old School Children. The Internet Journal of Epidemiology ISSN: 1540-2614.

8. Krawczyk D, Pels E1, Prucia G, Kosek K, Hoehne D. Students' knowledge of oral hygiene vs its use in practice. Advances in Medical Sciences Suppl.1. 2006;(51):122125.

9. $\mathrm{MOH}$ Nursing clinical practice guidelines 1/2004. Nursing Management of Oral Hygiene. December 2004;1:1-40.

10. Arold D Sgan-Cohen Oral hygiene improvement: a pragmatic approach based upon risk and motivation levels BMC Oral Health 2008;8:31-33.

11. Faveri M, Hayacibara MF, Pupio GC, Cury JA, Tsuzuki CO, Hayacibara RM. Across-over study on the effect of various therapeutic approaches to morning breath odour. Clin Periodontol 2006;33:555-560.

12. Söder B, Johansson B, Söder PO. The relation between foetor ex ore, oral hygiene and periodontal disease. Swed Dent J. 2000;24(3):73-82. 
13. Pratibha PK, Bhat KM, Bhat GS. Oral malodor: a review of the literature. 1: $\mathrm{J}$ Dent Hyg. Summer, Jul,2006;80(3):8.

14. Beverage Council of Ireland Position Paper August 2007.[online].cited on 09.06.09]. Available from L:http://www.beveragecouncilofireland.ie/ attachments/222

15. Gordon Y, Reddy J. prevalence of dental caries, patterns of sugar consumption and oral hygiene practices in infancy in $\mathrm{S}$. Africa. Community Dentistry and Oral Epidemiology. May 2006;13(6):310-314.

16. How to practice Good dental hygiene .[online].[cited on 10.05.09]. Available from

URL://http://www.howtodothings.com/

17. Sogi G, Bhasker DJ. Dental caries and oralhygien status of 13-14 year old schoolchildren of Davangeri. J Indian Soc Prev Dent 2001;113-117.
18. Mumghamba EG, Manji KP, Michael J. Oral hygiene practices, periodontal conditions, dentition status and selfreported bad mouth breath among young mothers, Tanzania. Int J Dent Hyg. 2006 Nov;4(4):166-73.

19. Nalçacı R, Sönmez I S. Evaluation of oral malodor in children. Oral Surg Oral Med Oral Pathol Oral Radiol Endod 2008;106:384-8.

20. Sanz M, Roldan S, Herrera D. Fundamentals of Breath Malodour. Journal of Contemporary Dental Practice. 2001 Nov;4(2):001-017.

21. Goyal A, Gauba K,Chawla HS, Kapur A. Epidemiology of dental caries in Chandigarh School children and trends over the last 25 years. J Indian Soc PedodPrevent Dent September 2007:115118. 